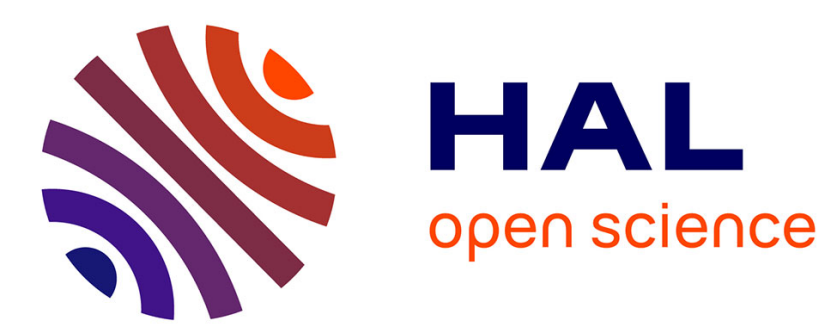

\title{
Competition, R\&D and the cost of innovation
}

Philippe Askenazy, Christophe Cahn, Delphine Irac

\section{To cite this version:}

Philippe Askenazy, Christophe Cahn, Delphine Irac. Competition, R\&D and the cost of innovation. 2008. halshs-00586690

\section{HAL Id: halshs-00586690 \\ https://shs.hal.science/halshs-00586690}

Preprint submitted on 18 Apr 2011

HAL is a multi-disciplinary open access archive for the deposit and dissemination of scientific research documents, whether they are published or not. The documents may come from teaching and research institutions in France or abroad, or from public or private research centers.
L'archive ouverte pluridisciplinaire HAL, est destinée au dépôt et à la diffusion de documents scientifiques de niveau recherche, publiés ou non, émanant des établissements d'enseignement et de recherche français ou étrangers, des laboratoires publics ou privés. 


\section{PARLS SCHOOL OF ECONOMICS}

WORKING PAPER N²008 - 32

Competition, R\&D and the cost of innovation

Philippe Askenazy

Christophe Cahn

Delphine Irac

JEL Codes: L51, O31

Keywords: Competition, R\&D, innovation

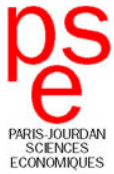




\title{
Competition, R\&D, and the Cost of Innovation*
}

\author{
Philippe Askenazy ${ }^{\dagger} \quad$ Christophe Cahn ${ }^{\dagger, \ddagger} \quad$ Delphine Irac $^{\ddagger}$
}

May 29, 2008

\begin{abstract}
This paper proposes a model in the spirit of Aghion et al. (2005) that relates the magnitude of the impact of competition on R\&D to the cost of innovation. The effect of competition on R\&D is an inverted U-shape. However, the shape is flatter and competition policy is therefore less relevant for innovation when innovations are relatively costly. Intuitively, if innovations are costly for a firm, competitive shocks have to be significant to alter its innovation decisions. Empirical investigations using a unique panel dataset from the Banque de France show that an inverted U-shaped relationship can be clearly evidenced for the largest firms, but the curve becomes flatter when the relative cost of R\&D increases. For large costs, the relationship even vanishes.
\end{abstract}

KEYWORDS: Competition, R\&D, innovation.

JEL Classification: L51, O31.

${ }^{*}$ We thank participants at Banque de France and GREQAM seminars, ESEM-07, and the CEPR-Banque de France conference on Innovation at Enghien les Bains, especially Philippe Aghion, Martine Carré, Gilbert Cette, Rachel Griffith, and Jacques Mairesse for comments on earlier versions. We are also grateful to Nicolas Berman and Laurent Eymard for valuable research assistance. We retain sole responsibility for any remaining errors. The views expressed herein are those of the authors and do not necessarily reflect those of the affiliated institutions.

${ }^{\dagger}$ Paris School of Economics, IZA, and Banque de France. askenazy@pse.ens.fr.

${ }^{\ddagger}$ Banque de France, DAMEP. christophe.cahn@pse.ens.fr, delphine.irac@banque-france.fr. 


\section{Introduction}

Aghion et al. $(2002,2005)$ attempt to reconcile the Schumpeterian view of innovation enhancing monopoly position and the escape-competition approaches in a unique model. Their model exhibits an inverted U-shape relationship between innovation and competition: competition may increase the innovation profit margin for firms close to the technological frontier (since they escape competition) but strong competition could also reduce incentives to innovate for laggards (disincentive effect). This prediction meets evidence on a panel of UK listed firms and is also consistent with results on large French firms, as this paper shows.

However, when extending the sample to smaller firms, there is no empirical evidence that these mechanisms apply, at least on our dataset of French firms. Hence we start by considering the following economic puzzle: what could explain that this inverted-U relationship between innovation and competition does not hold when considering the whole industry structure of an economy like France, whereas empirical evidence support it when restricting to the larger firms? Theoretically, size may matter: if innovations are large-scale and costly in the firm's sector or relatively to the size of the firm, competitive shocks have to be large enough to change its innovation choices.

Thereafter, we attempt in this paper to economically approach this puzzle by providing an appropriate theoretical framework describing the impact of competition on innovation behavior which applies empirically for all size of firms and competition cost. The main prediction of the model is that the Aghion et al. (2005) inverted U-shape is flatter and competition policy is therefore less relevant for innovation when innovations are costly or firm size is small.

Empirical investigations using a unique panel dataset from the Banque de France confirm a clear inverted U-shaped relationship for the largest French firms. But the curve flattens when the cost of innovation at the sectoral level or relative to the firm's size becomes large: changes in the competitive position of the firm does not seem robustly associated with changes in $R \& D$ intensity. For large costs, the relationship even vanishes: competition does not seem to impact firm R\&D behavior.

These results are also related to the literature on innovation decisions that stresses the role of firm size (e.g. Cohen and Klepper, 1996). It may be easier to finance R\&D in large firms because they may have a reputation and enjoy deeper relations with external investors or bank lenders. They may also gain through a "too big to fail" mechanism. Finally, because of sunk costs 
associated with innovation investment, large firms have more incentive to engage in innovative activities. Empirical evidence seems to support this view. ${ }^{1}$

The paper is organized as follows. Section 2 is devoted to detail the model and the theoretical predictions. Econometric strategies and data are presented in section 3, that also provides the key empirical findings. Some perspectives are given in a last section.

\section{Theoretical framework}

\subsection{Basic elements of the model}

We present in this section a simple model that can encompass the role of the cost of innovation and the market's — or similarly the firm's - size as regards the impact of competition on R\&D. This model is an extension of the standard Aghion et al. (2005)'s framework.

\section{Households and final goods}

We assume that a unit mass of homogenous households supplying labor inelastically seeks to maximize discounted sum of logarithmic instantaneous utility flows with a constant rate $r$. The argument of these utility functions is the consumption good $y$ which is produced according to the following production function $\ln \left(y_{t}\right)=\int_{0}^{1} \Phi_{j} \ln \left(x_{j t}\right) \mathrm{d} j$ with $\Phi_{j}>0 \forall j$ and $\int_{0}^{1} \Phi_{j} \mathrm{~d} j=1$, where $\Phi_{j}$ represents the weight in the utility function of intermediate input $x_{j}{ }^{2}$ Intermediate goods $j$ are yielded by duopolists $A$ and $B$ that combine their perfectly substitutable production according to the relation $x_{j}=x_{A j}+x_{B j}$. The assumptions upon which the model is built allow us for choosing the numeraire for the prices of intermediate goods in each sector by normalizing the households' current expenditure in good $j$ proportionally to its weight in the utility function, such that $p_{j} x_{j}=\Phi_{j}$.

\section{Intermediate production}

Intermediate firms produce goods from labor with constant returns to scale taking the wage rate as given, which leads to independent of quantities produced unit cost of production for each duopolist. Contrary to Aghion et al. (2005), we can not normalize labor to one because $\Phi_{j}$ 's are heterogeneous. ${ }^{3}$ We assume that one unit of labor employed by each intermediate duopolist generates outflow equal to:

$$
\Gamma_{i}=\gamma^{k_{i}}, \quad i=\{A, B\},
$$

\footnotetext{
${ }^{1}$ For example, Savignac (2007) shows that French firms with plans to innovate face financial constraints that reduce the likelihood of their embarking on such projects, and that these constraints decrease with firm size.

${ }^{2}$ Note that Aghion et al. (2005) take a particular form for which $\Phi_{j}=1 \forall j$.

${ }^{3}$ In the remaining part of the paper, sectoral subscript $j$ is omitted as long as it does not create confusion.
} 
where $k_{i}$ is the technology level of duopoly firm $i$ in a certain sector, and $\gamma>1$ is the size of the leading-edge innovation. The total output of a duopolist is

$$
L_{i} \Gamma_{i}=L_{i} \gamma^{k_{i}}, \quad i=\{A, B\}
$$

where $L_{i}$ is the amount of labor devoted to production by the firm. By the same way, we define $\tilde{\pi}_{m}$ and $\tilde{\pi}_{-m}$ to be the equilibrium profit flow by employee of a firm $m$ steps ahead, respectively behind, its rival. Hence, the economy is composed of two types of sector: either leveled (neckand-neck) type, where there is no technology gap, or unleveled where a leader and a follower coexist. As Aghion et al. (2005), we have to restrict $m=1$ in order to be able to obtain a closed-form solution for the model. This means that the maximum sustainable gap is one: if a leader innovates, then the follower can imitate immediately the leader's past technology with no cost.

\section{$\mathbf{R} \& \mathbf{D}$}

We assume a $\mathrm{R} \& \mathrm{D}$ cost function $\psi(n)=\beta n^{2} / 2$, where $\beta$ is an increasing function of the size of innovation $\gamma$ with $\lim _{\gamma \rightarrow 1} \beta=0 . \psi(n)$ defines the total cost that a leading firm have to spend to gain one technological step according to a Poisson process of parameter $n$. This cost can also be spent by a following firm to move a step forward with hazard rate $n+h$, where $h$ represents the opportunity gain to copy the leader, even if no R\&D efforts are made. From now, $n_{0}$ denotes the R\&D efforts of each firm in a neck-and-neck sector and $n_{1}$ (resp. $\left.n_{-1}\right)$ those of a leader (resp. follower) firm in a unleveled industry. ${ }^{4}$

\section{Product market competition}

To complete the model, we describe the profit flow for each type of intermediate firms. In each unleveled sector, all profits are kept by the leader firm, say $A$ for instance, so that it receives the difference between its revenue $p_{A} x_{A}$ and the total cost of production $c_{A} x_{A}$, where $p_{A}$ and $c_{A}$ are respectively the price and the production cost of one unit produced by the leader firm. The market structure à la Bertrand inside the sector implies that the leader's price equals production cost of the follower. Because of perfect substitution among intermediate goods and the Bertrand competition, the follower does not produce and makes no profit. But the firm still exists and may for example conduct research in order to reach the technological frontier. Based on our normalization, we have thus $c_{A} x_{A}=c_{A} \Phi / p_{A}=c_{A} \Phi / c_{B}$. Since one unit of labor can produce $\gamma^{k_{i}}$ units of goods for $i \in\{A, B\}$, firms need $x_{i} / \gamma^{k i}$ units of labor to produce $x_{i}$. So the unit cost

\footnotetext{
${ }^{4}$ It is worthwhile to bear in mind that the catch-up process prevents the leader firm to innovate, so that its R\&D efforts $n_{1}$, are zero.
} 
of production is $c_{i}=\omega / \gamma^{k_{i}}$, where $\omega$ is the wage rate assumed to be the same among the firms. Hence, we have $c_{A} x_{A}=\Phi \gamma^{k_{B}-k_{A}}=\Phi \gamma^{-1}$. As a result, profits of the leader firm are given by $\tilde{\pi}_{1}=\pi_{1} \Phi$ with $\pi_{1}=1-\gamma^{-1}$. On the contrary, follower firm makes no profit so that $\tilde{\pi}_{-1}=0$.

As regards neck-and-neck industries, the profit flows depend on which extent the duopolists collude, according to the assumption of a competition à la Bertrand. As a result, the profit of a leveled firm is comprised between zero and the half of what a monopolist could earn, which leads to $\tilde{\pi}_{0}=\pi_{0} \Phi=\varepsilon \pi_{1} \Phi$, with $0 \leqslant \varepsilon \leqslant 1 / 2$ and $\nu=1-\varepsilon$ is a global measure of product market competition.

Furthermore, it is worth noting that the size of duopolists of sector $j$ is directly related - more precisely proportional - to the magnitude of its nominal demand. Indeed, according to the model and assuming a constant wage rate $\omega$, the workforce of firms in leveled sector is given by:

$$
L_{\text {neck-and-neck }}=\frac{\Phi}{2 \omega}\left(1-2 \pi_{0}\right)
$$

whereas the leader firm's size can be written as

$$
L_{\text {leader }}=\frac{\Phi}{\omega}\left(1-\pi_{1}\right)
$$

\subsection{Equilibrium research efforts}

\section{Bellman equations}

This subsection determines the equilibrium conditions in the model. Let $V_{-1}, V_{1}$, and $V_{0}$ denote respectively the steady state value of being currently a follower, a leader, and a neck-and-neck firm. We have standard Bellman asset equations:

$$
\begin{aligned}
r V_{1} & =\pi_{1} \Phi+\left(n_{-1}+h\right)\left(V_{0}-V_{1}\right), \\
r V_{-1} & =\pi_{-1} \Phi+\left(n_{-1}+h\right)\left(V_{0}-V_{-1}\right)-\beta \frac{n_{-1}^{2}}{2}, \\
r V_{0} & =\pi_{0} \Phi+n_{0}\left(V_{1}-V_{0}\right)+\bar{n}_{0}\left(V_{-1}-V_{0}\right)-\beta \frac{n_{0}^{2}}{2},
\end{aligned}
$$

where ex post $\bar{n}_{0}=n_{0}$ represents the R\&D intensity by the other duopolist in a leveled sector, which is identical in the Nash equilibrium. The first order conditions give:

$$
\begin{aligned}
V_{0}-V_{-1} & =\beta n_{-1} \\
V_{1}-V_{0} & =\beta n_{0} .
\end{aligned}
$$

According to these first order conditions, as an increase in market competition diminishes profits of a leveled firm, and consequently its market value, $V_{0}$ decreases and one could expect 
an increase of $n_{0}$ and a decline in $n_{-1}$, as schematically described by Figure 1 . Therefore, these effects are less pronounced when the size, and a fortiori the cost of innovation $\beta$, increases.

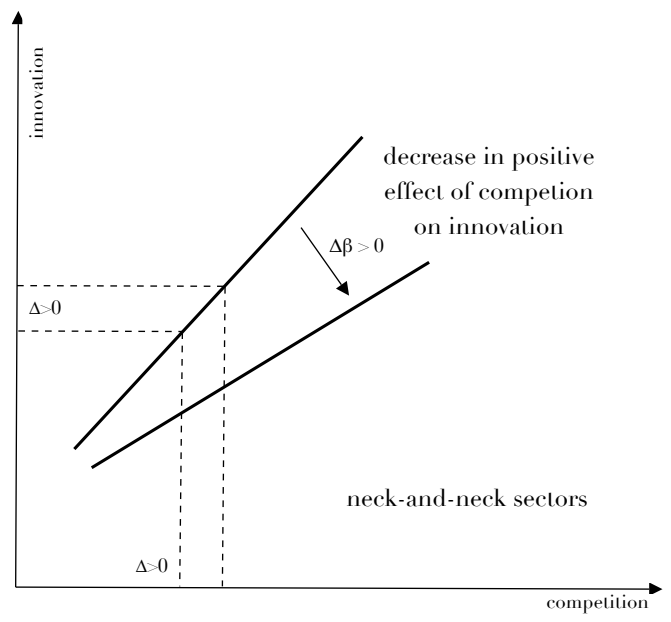

(a) Neck-and-neck sectors

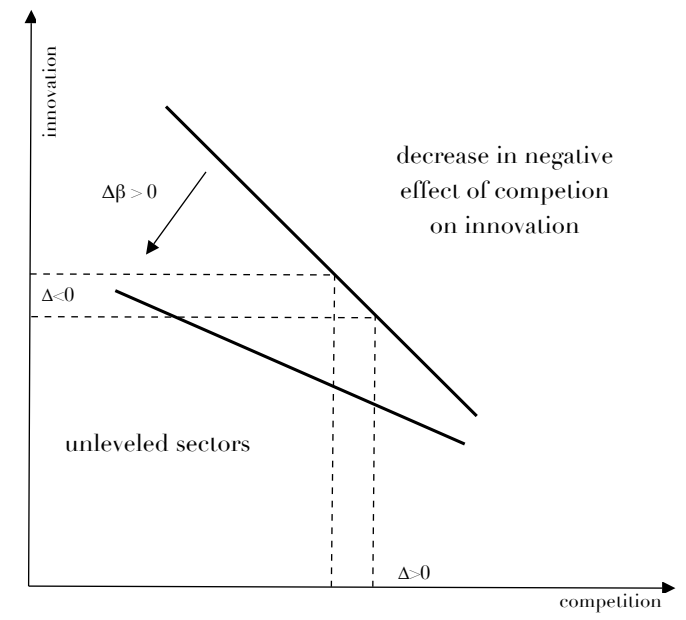

(b) Unleveled sectors

Figure 1: Impact of competition on innovation according to the cost of innovation

The next section formalizes these properties.

\subsection{Analytical solutions}

First order conditions combined with the Bellman equations imply the following reduced form R\&D equations :

$$
\begin{aligned}
\beta \frac{n_{0}^{2}}{2}+\beta(r+h) n_{0}-\left(\pi_{1}-\pi_{0}\right) \Phi & =0 \\
\beta \frac{n_{-1}^{2}}{2}+\beta\left(r+h+n_{0}\right) n_{-1}-\pi_{0} \Phi-\beta \frac{n_{0}^{2}}{2} & =0
\end{aligned}
$$

\section{Neck-and-Neck sector}

The solution of equation (10) gives the equilibrium research intensity for the leveled firm:

$$
n_{0}=-(r+h)+\sqrt{(r+h)^{2}+\frac{2 \nu \pi_{1} \Phi}{\beta}}
$$

Taking into account the extend of innovation, we have the following proposition: ${ }^{5}$

\footnotetext{
${ }^{5}$ This property includes the Aghion et al. (2005)' result that the R\&D efforts in neck-and-neck sectors, $n_{0}$, is an increasing function in the competition index.
} 
Proposition 1 Assuming a convex shape in the cost of innovation for $\beta$, the slope of the relationship between innovation and competition in the neck-and-neck sectors is a non negative, decreasing function of the size of innovation $\gamma$.

\section{Proof. See Appendix A}

The size of the demand for intermediate good could improve the relationship established in Proposition 1, as described in the following corollary:

Corollary 1 For a given size of innovation, the lower the size of the demand $\Phi$, the lower the effect of competition on research activities in the leveled sector.

Proof. See Appendix A

The intuition behind proposition 1 and corollary 1 relies on the fact that for industries where costly innovations take place, gains in terms of research efforts are mitigated by the limited impact of competition on firms' decision to innovate. On the contrary, R\&D activities are stimulated in sectors related to cheap innovations in order to escape from competition with less difficulties. Furthermore, these effects are more pronounced in large firms related to sectors for which the demand is large.

\section{Unleveled sector}

As for the neck-and-neck sectors, we find in a similar way the equilibrium research intensity for the laggard firm from equation (11):

$$
n_{-1}=-\left(r+h+n_{0}\right)+\sqrt{(r+h)^{2}+n_{0}^{2}+\frac{2 \pi_{1} \Phi}{\beta}}
$$

Once again, taking into account the cost of innovation, we have the following proposition: ${ }^{6}$

Proposition 2 The slope of the relationship between innovation and competition in the unleveled sectors is a non positive, increasing function of the size of innovation $\gamma$.

\section{Proof. See Appendix A}

This proposition comes together with the following corollary:

Corollary 2 For an either small or large innovation, the lower the extend of the demand $\Phi$, the lower the effect of competition on research activities in the unleveled sector.

\footnotetext{
${ }^{6}$ This property induces the Aghion et al. (2005)' result that the R\&D efforts in unleveled sectors, $n_{-1}$, is a decreasing function in the competition index.
} 
Proof. Demonstration follows proof of corollary 1.

\section{Aggregate innovation}

We now derive the aggregate flow of innovations $I$ from $\mu_{1}$ and $\mu_{0}$ which represents the steadystate probability of being an unleveled and a neck-and-neck industry respectively, with $\mu_{1}+$ $\mu_{0}=1$. The steady-state probability that a sector moves from an unleveled to leveled state is $\mu_{1}\left(n_{-1}+h\right)$. The reverse move appears with a steady-state probability of $2 \mu_{0} n_{0}$. In the steady-state we have $\mu_{1}\left(n_{-1}+h\right)=2 \mu_{0} n_{0}$. Hence, the aggregate flow of innovations is given by:

$$
I=\int_{\left\{\Phi_{j}\right\}_{0}^{1}} \frac{4 n_{0}\left(n_{-1}+h\right)}{2 n_{0}+n_{-1}+h} .
$$

Implicitly $I$ is a function of $\nu$ and $\gamma$. For a given firm, the expectation of its flow of innovation is proportional to $I(\nu, \gamma)$. This last equation (20) leads to the inverted-U relationship between competition and innovation as stated by Aghion et al. (2005). Nevertheless, based on the two previous propositions, the shape of this relationship is dependant of the overall cost of innovations that occur in the economy. Hence, the following theorem holds:

Theorem 1 The more the cost of global innovation in a given economy, the flatter the inverted$U$ relationship between competition and research activities in this economy.

Proof. The theorem is directly established according to both propositions 1 and 2 . Figure 2 depicts the shape of the relationship when the size of innovation varies. ${ }^{7}$

\section{Empirical findings}

The goal of this section is to illustrate the main theoretical predictions on French firms panel data: (i) the relationship between firm innovation flow $n$ and competition $\nu$ is inverted-U shape and (ii) this curve is flatter for higher size of innovation $\gamma$ and for lower magnitude of the demand $\Phi$ or alternatively the firm workforce. ${ }^{8}$

\subsection{Data}

We use two datasets: first, firm-panel data from the observatory of firms at the Banque de France; second, the French R\&D survey from the French ministry of research. ${ }^{9}$

\footnotetext{
${ }^{7}$ One can derive the analytical expression for the maximum as it leads to solve a $3^{\text {rd }}$-order polynomial equation. As these computations are cumbersome and could alter the clarity of our main purpose, we prefer to show numerical simulation.

${ }^{8}$ According to equations (3) and (4), these two variables are proportional.

${ }^{9}$ Systematic data cleaning was implemented: firms with negative Lerner index were deleted, and outliers were identified by Tukey method based on the interquartile gap of the variable (see Kremp, 1995).
} 


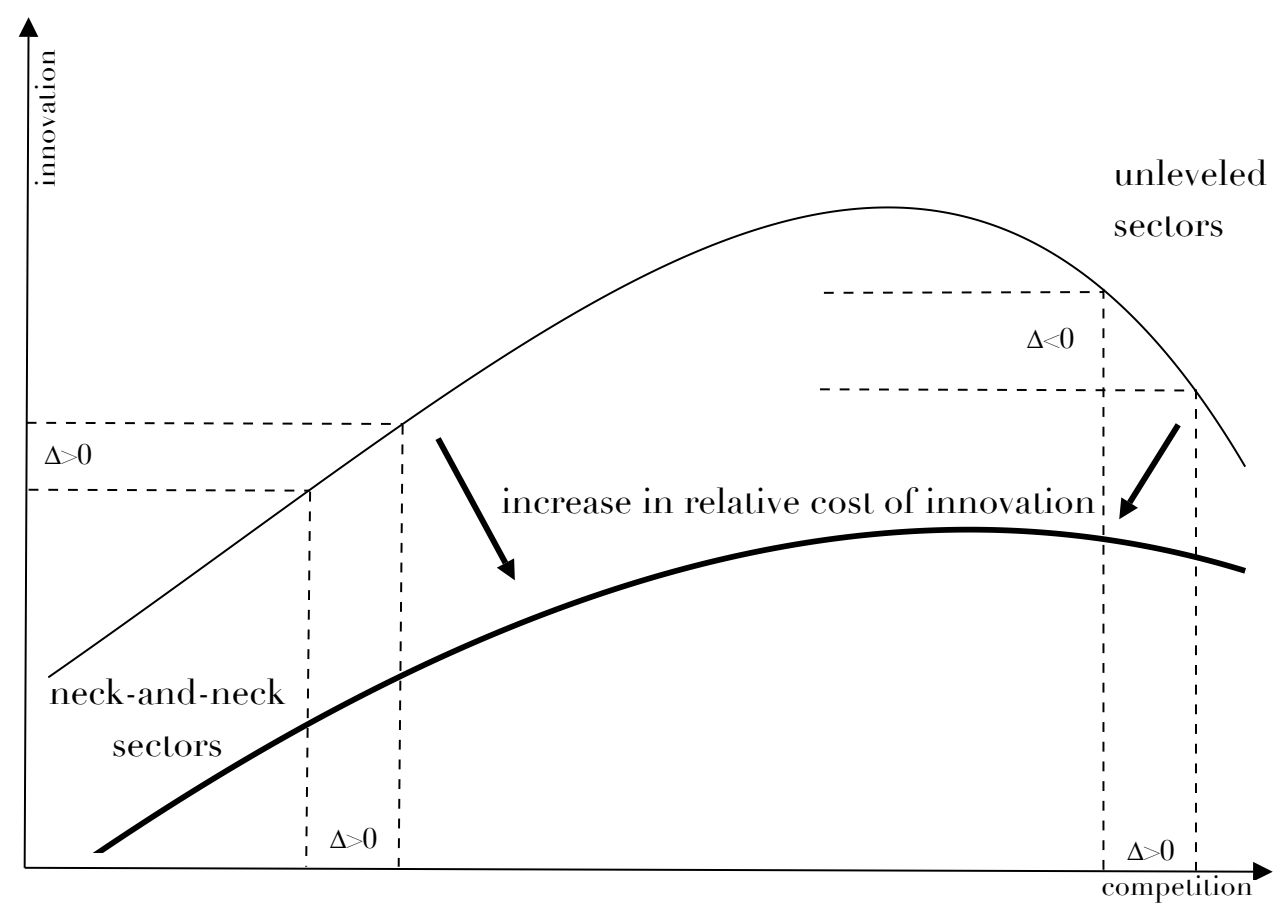

Figure 2: The inverted-U relationship with a varying cost of innovation

\section{R\&D and competition measures}

The two main variables of interest in the regressions, namely the $R \& D$ effort and the competition index, come from the Fiben and Centrale des Bilans databases (Banque de France Balance Sheet dataset). They are collected on a voluntary basis. Clerks in the different local establishments of the Bank of France contact firm to complete a survey. The Fiben database is based on firms tax forms and includes all businesses with more than 500 employees and a fraction of smaller firms. It covers about $57 \%$ of employment for manufacturing but less for service sectors. The advantage of this base is to include firm that have episodic R\&D activities or novel firms. We focus on firms that have conducted observable R\&D activities at least one year. Our unbalanced sample includes about 16,000 firms from 1990 to 2004. The sectoral distribution of observations is given in appendix.

A Lerner index for each firm can be built using these data. We only observe sectoral price provided by the INSEE, but we have detailed information on costs. The Lerner index is supposed to measure the market power of the firm by the difference between price and marginal costs (which equals the negative inverse of demand elasticity). Since neither price nor marginal costs are available at the firm level, we compute the index using operating profits minus the cost of capital over sales. The cost of capital is estimated using the formula that Chatelain and Tiomo 
(2001) and Chatelain et al. (2003) have specifically developed for the Fiben database; the latter contains very detailed balance sheet information that enables to compute these indicators. ${ }^{10} \mathrm{We}$ show in appendix A.4 that in our model the theoretical Lerner index is decreasing with $\nu$, the measure of competition.

\section{Cost of innovation}

In addition, we exploit the annual R\&D survey from the French Ministry of research. It includes information about total R\&D expenditure and the number of patents for around 3000 firms. The question about the number of patents exists since 1999 only. Thus we use the 1999 to 2002 waves. The survey targets firms that are likely to do research and development. One flaw of this survey is that it covers well known firms that do research on a continuous basis pretty well whereas its quality is much smaller regarding firms that do research on an occasional basis only. We assume that this survey provides relevant information about the average cost of a patent for a given sector (3 first digits of the NAF 700).

\subsection{Proxy for innovation flow}

In order to take the model to the data, we first have to estimate the flow of innovation. This flow, $n$, and the amount of $\mathrm{R} \& \mathrm{D}$ are related to each other according to $n=\mathrm{R} \& \mathrm{D} / \kappa$, where $\kappa$ is the estimated innovation unit cost.

The innovation unit cost is specific to a given sector and computed under the hypothesis that innovations are systematically patented. It is computed from the R\&D survey of the French Ministry of Finance for 142 sectors, with for each sector $s$ :

$$
\kappa_{s}=\frac{\mathrm{R} \& \mathrm{D} \text { in sector } s}{\text { number of patents in sector } s} .
$$

Both variables of the right hand side are taken from the $R \& D$ survey. $R \& D$ and number of patents in sector $s$ are taken as an average over 1999-2002. The average cost of a patent is around 1 million euros and the cost in the median sector is 860 thousands euros. Among sectors with low patent costs (below 150,000 euros) we find old sectors like wood, fabrication involving clay, fabrication of tiles etc. Sectors with high patent costs are more recent sectors (data processing, fabrication of electronic devices processing image and sound etc.).

It is then possible to derive a potential flow of innovation $n_{j}$, for each firm $j$, by the ratio:

$$
n_{j}=\frac{\mathrm{R} \& \mathrm{D} \text { of firm } j}{\kappa_{s}} .
$$

\footnotetext{
${ }^{10}$ Using the standard mnemonics of French tax forms: Lerner $=[\mathrm{VA}-(\mathrm{AQ}+\mathrm{AS}+\mathrm{AU}+\mathrm{AW}+\mathrm{AY}-\mathrm{AQ}-1-\mathrm{AS}-1-\mathrm{AU}-$ 1-AW-1-AY-1)-0.085.capital-(DR-DR-1)]/FL.
} 
$\mathrm{R} \& \mathrm{D}$ of firm $j$ is measured as investment in R\&D taken from FIBEN (variable KC of a standard $\operatorname{tax}$ form). ${ }^{11}$

Noticeably, this flow of patents is not directly observed from a patent database but estimated from the R\&D effort. Indeed, what we really have in mind is less to measure the observed flow of patents than to get a proxy for the innovation which potentially stems from the $R \& D$ effort of the firm. The flow of innovation $n_{j}$ is therefore firm specific and time specific. It can be interpreted as the potential number of patents that the firm is likely to register given the amount she devotes to $\mathrm{R} \& \mathrm{D}$ and the sectoral patent unit cost. This flow of innovation is subsequently used in the econometric investigation.

\subsection{Econometric strategy}

To approximate the inverted- $U$ shape and to take into account the interactions with both the size of innovation and the size of the firm, we use a quadratic form. Precisely we estimate the model:

$$
\begin{aligned}
& I_{j, t}=n_{j, t}=\lambda_{j, t}^{2}\left\{-\alpha_{1}+\alpha_{2} \cdot \ln \left(\text { innovation_cost }_{\mathrm{s}}\right)-\alpha_{3} \cdot \ln \left(\text { firm_workforce } \mathrm{j}_{\mathrm{j}, \mathrm{t}}\right)\right\}+\cdots \\
& +\lambda_{j, t}\left\{\delta_{1}-\delta_{2} \cdot \ln \left(\text { innovation_cost }_{\mathrm{s}}\right)+\delta_{3} \cdot \ln \left(\text { firm_workforce }_{\mathrm{j}, \mathrm{t}}\right)\right\}+c_{j}+c_{t}+\epsilon_{j, t},
\end{aligned}
$$

where, $\lambda_{j, t}$ is the firm Lerner index, $c_{t}$ is a year dummy in order to correct for the overall business cycle and $c_{j}$ is a firm fixed effect that encompasses fixed firm characteristics (sector, average workforce, etc.). The cost of innovation is the patent unit cost $\kappa_{s}$. Firm size is measured as the number of employees.

\subsection{Results}

\subsubsection{Inverted-U shape without cost effect}

Recall that Aghion et al. (2005) found an inverted-U relationship among firms listed on the London Stock Exchange. Thus, before estimating the full model, we check if we find also a such inverted-U-shaped curve for France, i.e. without interaction terms (Table 1). Estimation on the full sample of innovative firms does not support the quadratic form, and consequently the inverted-U shape (column 1). Rather, there is a significant linear relation: more competition is positively associated with more $R \& D$.

\footnotetext{
${ }^{11}$ Total expenditures in $\mathrm{R} \& \mathrm{D}$ are available only on a smaller subsample (Centrale des Bilans.)
} 
Table 1: The U-inverted shape excluding size effect

\begin{tabular}{|c|c|c|}
\hline \multicolumn{3}{|c|}{ Dependant variable: potential flow of innovation, $n_{j, t}$} \\
\hline & $(1)$ & $(2)$ \\
\hline Lerner $_{t-1}^{2}$ & $\begin{array}{c}0.0033 \\
(0.47)\end{array}$ & $\begin{array}{c}-3.5160^{* * *} \\
(-3.63)\end{array}$ \\
\hline Lerner $_{t-1}$ & $\begin{array}{c}-0.0618^{* * *} \\
(-2.81)\end{array}$ & $\begin{array}{c}2.1688^{* *} \\
(2.35)\end{array}$ \\
\hline Years & yes & yes \\
\hline Firm fixed effects & yes & yes \\
\hline Number of obs. & 100,092 & 1,866 \\
\hline Number of firms & 15,593 & 359 \\
\hline$R^{2}$ & 0.58 & 0.61 \\
\hline \multicolumn{3}{|c|}{$\begin{array}{l}\text { Estimation of the inverted-U shape (E) excluding size effect on a full } \\
\text { panel of French innovative firms (column } 1 \text { ) and on the } 2 \% \text {-largest firms } \\
\text { in terms of real value added (column } 2 \text { ), over the period } 1991 \text { to } 2004 \text {. } \\
\text { Robust } t \text {-stat in parentheses. }{ }^{*} \text { significant at } 10 \%,{ }^{* *} \text { significant at } 5 \% \text {, } \\
{ }^{* * *} \text { significant at } 1 \% \text {. }\end{array}$} \\
\hline
\end{tabular}

But, if we restrict the panel to the $2 \%$-largest firms in terms of real value added (column 2, Table 1), which should be more similar to a panel of listed firms, the figure is dramatically different: the quadratic relation becomes statistically significant, leading to an inverted-U shaped curve. The top of the curve is obtained for reasonable lerner of 0.31 . The clear different findings between the 2 samples, constitute a first hint of the relevance of the cost/size effect, and consequently of the inclusion of interaction terms in the empirical estimations.

\subsubsection{Including cost effect}

Table 2 provides estimations of the full econometric model including interaction terms. ${ }^{12}$ For all specifications, a quadratic function seems a correct specification of how innovation and competition relates to each other: $\alpha_{1}$ and $\delta_{1}$ are positive and significant. Therefore, if the innovation cost was extremely low or, to put it differently, innovations could be implemented with extremely small magnitude in an incremental way, the interaction terms would be negligible and the inverted-U relationship would fully apply.

\footnotetext{
${ }^{12}$ Additional estimations on subsamples in order to check for outliers have been implemented: results are not affected.
} 
Table 2: The cost of innovation and the magnitude of the U-inverted shape

\begin{tabular}{|c|c|c|c|c|}
\hline \multicolumn{5}{|c|}{ Dependant variable: potential flow of innovation, $n_{j, t}$} \\
\hline & $(1)$ & $(2)$ & $(3)$ & (4) \\
\hline Lerner $_{t-1}^{2}$ & $\begin{array}{c}-0.5268^{* * *} \\
(-3.64)\end{array}$ & $\begin{array}{c}0.0749^{* *} \\
(2.48)\end{array}$ & $\begin{array}{c}-0.9277^{* * *} \\
(-4.40)\end{array}$ & $\begin{array}{c}-0.5644^{* *} \\
(-2.48)\end{array}$ \\
\hline Lerner $_{t-1}^{2} \cdot \ln \left(\kappa_{s}\right)$ & $\begin{array}{c}0.0802^{* * *} \\
(3.65)\end{array}$ & - & $\begin{array}{c}0.1525^{* * *} \\
(4.59)\end{array}$ & - \\
\hline Lerner $_{t-1}^{2} \cdot \ln ($ workforce $)$ & - & $\begin{array}{c}-0.0837^{* *} \\
(-2.28)\end{array}$ & $\begin{array}{c}-0.0955^{* *} \\
(-2.50)\end{array}$ & $\begin{array}{l}- \\
-\end{array}$ \\
\hline Lerner $_{t-1}^{2} \cdot \ln \left(\kappa_{s} /\right.$ workforce $)$ & - & - & - & $\begin{array}{c}0.0982^{* * *} \\
(2.60)\end{array}$ \\
\hline Lerner $_{t-1}$ & $\begin{array}{c}0.5797^{* * *} \\
(4.29)\end{array}$ & $\begin{array}{c}-0.1866^{* * *} \\
(-3.89)\end{array}$ & $\begin{array}{c}0.7226^{* * *} \\
(4.33)\end{array}$ & $\begin{array}{c}0.4510^{* * *} \\
(2.98)\end{array}$ \\
\hline Lerner $_{t-1} \cdot \ln \left(\kappa_{s}\right)$ & $\begin{array}{c}-0.0967^{* * *} \\
(-4.99)\end{array}$ & - & $\begin{array}{c}-0.1380^{* * *} \\
(-5.89)\end{array}$ & - \\
\hline Lerner $_{t-1} \cdot \ln ($ workforce $)$ & - & $\begin{array}{c}0.0859^{* * *} \\
(3.58)\end{array}$ & $\begin{array}{c}0.0938^{* * *} \\
(3.79)\end{array}$ & - \\
\hline Lerner $_{t-1} \cdot \ln \left(\kappa_{s} /\right.$ workforce $)$ & - & - & - & $\begin{array}{c}-0.0982^{* * *} \\
(-4.20)\end{array}$ \\
\hline Years & yes & yes & yes & yes \\
\hline Firm fixed effects & yes & yes & yes & yes \\
\hline Number of obs. & 100,041 & 99,556 & 99,556 & 99,556 \\
\hline Number of firms & 15,586 & 15,527 & 15,527 & 15,527 \\
\hline$R^{2}$ & 0.58 & 0.57 & 0.57 & 0.57 \\
\hline
\end{tabular}

Estimation of the inverted-U shape (E) including size effect on a full panel of French innovative firms over the period 1991 to 2004. Robust $t$-stat in parentheses. ${ }^{*}$ significant at $10 \%,{ }^{* *}$ significant at $5 \%,{ }^{* * *}$ significant at $1 \%$.

Column 1 of table 2 displays the regression coefficients of the estimated model when $\kappa$ is taken as the patent unit cost. Column 2 shows the results when introducing firm size only as a parameter of the curve. In column 3, both innovation cost and firm workforce are introduced to parameterize the link between innovation and competition. What clearly emerges from the estimation results is that a non linear relationship between innovation and competition seems to strongly hold when controlling for firm and innovation sizes. In column 1, the coefficients are correctly signed ( $\alpha$ 's and $\delta$ 's are positive), although the relation is almost flat for the majority of firms: given the distribution of $\ln (\kappa)$ (ranging from 4 to 9.5, see table 3 ), the coefficients of $\lambda^{2}$ and $\lambda$ are very close to zero. Working with firm size in column 2 gives a clear inverted-U 
shaped curve for all firms. Introducing both types of size simultaneously supports theorem 1 and corollaries 1 and 2 of section 2.3. The relationship between innovation and competition gets looser and looser as firm size decreases (corollaries 1 and 2) and as innovation size increases (theorem 1).

In a last stage (table 2, column 4), we work directly with the innovation cost per employee by restricting the two coefficients of innovation and firm size to be equal. Again, the curve gets flatter as the innovation cost per employee increases: for the median firm (for which the unit cost of patent is around 25,000 euros per employee), the maximum of the curve is obtained for reasonable value of the Lerner index (around 0.27). The estimated impact of competition on innovation is economically significant. Decreasing the lerner index from 0.35 to 0.27 , i.e. half of a standard deviation, should increase the innovation flow of median firm by about a quarter. But again, in sectors with more costly innovations the curve becomes flat. The impact of competition vanishes.

\subsection{Robustness}

\section{Patenting behaviour}

We perform two robustness checks. First, a literature discusses the accuracy of patents as a measure of innovation flows. Patenting practices may differ widely across sectors. ${ }^{13}$

To cope with the intrinsic limits of patents as the proper metric to use for innovation, we restrict our sample to sectors for which patenting behaviour is relatively homogenous and in line with qualitative information we have about innovation. The Ministry of Research dataset includes a yes/no question of whether firms have innovated or not. In almost all the occurrences where firms have innovated do they file patents but, understandably, the converse is not true: the ratio of the number of patenting firms over the number of innovative firms by sector ranges from 0 to 1 with a median of 0.36 .

We re-estimate Table 2 on two subsamples for which this patenting-innovative ratio is not too low, with two thresholds: superior to 0.36 and to 0.50 ( $25 \%$ of the observations). Table 3 shows that the results are not affected by this condition on the patenting behaviour.

\section{Average versus marginal cost for Lerner Index Calculation}

\footnotetext{
${ }^{13}$ In certain sectors, firms rely much more on secrecy than on patents to protect their innovation (see Scherer and Ross, 1990, Chap. 17).
} 
Table 3: Robustness check for heterogeneous patenting behaviour biais

\begin{tabular}{|c|c|c|c|c|}
\hline \multicolumn{5}{|c|}{ Dependant variable: potential flow of innovation, $n$} \\
\hline & $(1)$ & $(2)$ & $(3)$ & (4) \\
\hline Lerner $_{t-1}^{2}$ & $\begin{array}{c}-0.7016 \\
(-1.04)\end{array}$ & $\begin{array}{c}-.6211^{* *} \\
(-2.35)\end{array}$ & $\begin{array}{c}-1.2980 \\
(-1.07)\end{array}$ & $\begin{array}{c}-0.8080^{* *} \\
(-2.00)\end{array}$ \\
\hline Lerner $_{t-1}^{2} \cdot \ln \left(\kappa_{s}\right)$ & $\begin{array}{c}0.2488^{* * *} \\
(2.69)\end{array}$ & - & $\begin{array}{c}0.3528^{* *} \\
(2.09)\end{array}$ & - \\
\hline Lerner $_{t-1}^{2} \cdot \ln ($ workforce $)$ & $\begin{array}{c}-0.2351^{* * *} \\
(-3.14)\end{array}$ & - & $\begin{array}{c}-0.2725^{* *} \\
(-2.31)\end{array}$ & - \\
\hline $\operatorname{Lerner}_{t-1}^{2} \cdot \ln \left(\kappa_{s} /\right.$ workforce $)$ & - & $\begin{array}{c}0.2372^{* * *} \\
(-3.75)\end{array}$ & - & $\begin{array}{c}0.2737^{* * *} \\
(2.64)\end{array}$ \\
\hline Lerner $_{t-1}$ & $\begin{array}{r}0.6907 \\
(1.42)\end{array}$ & $\begin{array}{c}0.3321^{*} \\
(1.67)\end{array}$ & $\begin{array}{l}1.1660 \\
(1.30)\end{array}$ & $\begin{array}{c}0.4011 \\
(1.33)\end{array}$ \\
\hline Lerner $_{t-1} \cdot \ln \left(\kappa_{s}\right)$ & $\begin{array}{c}-0.2124^{* * *} \\
(-3.33)\end{array}$ & - & $\begin{array}{c}-0.2715^{* *} \\
(-2.20)\end{array}$ & - \\
\hline Lerner $_{t-1} \cdot \ln ($ workforce $)$ & $\begin{array}{c}0.1500^{* * *} \\
(2.80)\end{array}$ & - & $\begin{array}{c}0.1420 \\
(1.61)\end{array}$ & - \\
\hline Lerner $_{t-1} \cdot \ln \left(\kappa_{s} /\right.$ workforce $)$ & - & $\begin{array}{c}-0.1650^{* * *} \\
(-3.74)\end{array}$ & - & $\begin{array}{c}-0.1585^{* *} \\
(-2.02)\end{array}$ \\
\hline Years & yes & yes & yes & yes \\
\hline Firm fixed effects & yes & yes & yes & yes \\
\hline Number of obs. & 53,765 & 53,765 & 25,842 & 25,842 \\
\hline Number of firms & 8,729 & 8,729 & 4,308 & 4,308 \\
\hline$R^{2}$ & 0.55 & 0.55 & 0.66 & 0.66 \\
\hline
\end{tabular}

Estimation of the inverted-U shape (E) including size effect on a full panel of French innovative firms over the period 1991 to 2004. Columns (1) and (2): patenting-innovative ratio higher than $36 \%$. Columns (3) and (4): patentinginnovative ratio higher than $48 \%$. Robust $t$-stat in parentheses. ${ }^{*}$ significant at $10 \%,{ }^{* *}$ significant at $5 \%,{ }^{* * *}$ significant at $1 \%$.

In the results we present, the lerner index is computed as a mark-up over average costs, whereas theoretically the index should be calculated using the marginal cost. In order to check whether our results do not hinge upon this assumption, once again, we restrict our sample to a subsample of firms for which fixed costs of production are likely to have already been covered. We select firms that have been created more than 25 years ago. The distribution of size is not dramatically changed by moving on this subsample. The first, second, and third quartiles of the number of employees are respectively 19, 39, and 93 employees for elder firms, whereas they are 
Table 4: Robustness check for Lerner index approximation.

\begin{tabular}{|c|c|c|c|c|}
\hline \multicolumn{5}{|c|}{ Dependant variable: potential flow of innovation, $n$} \\
\hline & $(1)$ & $(2)$ & $(3)$ & $(4)$ \\
\hline Lerner $_{t-1}^{2}$ & $\begin{array}{c}-1.6716^{* * *} \\
(-3.18)\end{array}$ & $\begin{array}{c}0.3689^{*} \\
(1.82)\end{array}$ & $\begin{array}{c}-1.2335^{* *} \\
(-2.33)\end{array}$ & $\begin{array}{c}-0.8373^{* * *} \\
(-3.13)\end{array}$ \\
\hline Lerner $_{t-1}^{2} \cdot \ln \left(\kappa_{s}\right)$ & $\begin{array}{c}0.2184^{* * *} \\
(3.07)\end{array}$ & - & $\begin{array}{c}0.2424^{* * *} \\
(3.27)\end{array}$ & - \\
\hline Lerner $_{t-1}^{2} \cdot \ln ($ workforce $)$ & - & $\begin{array}{c}-0.1640^{* *} \\
(-2.38)\end{array}$ & $\begin{array}{c}-0.1728^{* *} \\
(-2.47)\end{array}$ & - \\
\hline Lerner $_{t-1}^{2} \cdot \ln \left(\kappa_{s} /\right.$ workforce $)$ & - & - & - & $\begin{array}{c}0.1993^{* * *} \\
(3.43)\end{array}$ \\
\hline Lerner $_{t-1}$ & $\begin{array}{c}1.3057^{* * *} \\
(3.87)\end{array}$ & $\begin{array}{c}-0.3493^{* *} \\
(-2.33)\end{array}$ & $\begin{array}{c}0.9629^{* * *} \\
(2.79)\end{array}$ & $\begin{array}{c}0.5442^{* * *} \\
(3.10)\end{array}$ \\
\hline Lerner $_{t-1} \cdot \ln \left(\kappa_{s}\right)$ & $\begin{array}{c}-0.1829^{* * *} \\
(-4.17)\end{array}$ & - & $\begin{array}{c}-0.1971^{* * *} \\
(-4.40)\end{array}$ & - \\
\hline Lerner $_{t-1} \cdot \ln ($ workforce $)$ & - & $\begin{array}{c}0.1200^{* * *} \\
(2.62)\end{array}$ & $\begin{array}{c}0.1242^{* * *} \\
(2.70)\end{array}$ & - \\
\hline Lerner $_{t-1} \cdot \ln \left(\kappa_{s} /\right.$ workforce $)$ & - & - & - & $\begin{array}{c}-0.1498^{* * *} \\
(-4.11)\end{array}$ \\
\hline Years & yes & yes & yes & yes \\
\hline Firm fixed effects & yes & yes & yes & yes \\
\hline $\begin{array}{l}\text { Number of obs. } \\
\text { Number of firms } \\
R^{2}\end{array}$ & $\begin{array}{c}50,691 \\
6,585 \\
0.59\end{array}$ & $\begin{array}{c}50,479 \\
6,573 \\
0.56\end{array}$ & $\begin{array}{c}50,479 \\
6,573 \\
0.56\end{array}$ & $\begin{array}{c}50,479 \\
6,573 \\
0.56\end{array}$ \\
\hline
\end{tabular}

Estimation of the inverted-U shape (E) excluding firms created after 1982. Columns' specifications are the same as in Table 2. Robust $t$-stat in parentheses. ${ }^{*}$ significant at $10 \%,{ }^{* *}$ significant at $5 \%,{ }^{* * *}$ significant at $1 \%$.

15, 30, and 66 on the whole sample. As Table 4 shows, the findings of Table 2 still hold when working on this subsample.

\section{Perspectives}

Both theoretical predictions and empirical findings based on an appropriate framework support the mechanism that competition impacts firm decisions less when the cost of innovation in its sector is high in absolute terms or relative to its value added.

These results may have significant policy implications. The inverted U-shape already suggests that competition policy should be adjusted to take account of the state of the industry (Aghion et 
al., 2005). A second aspect of differentiation should be the nature of innovation in the industry. If innovations are costly, policy changes may have to be on a very large scale for an impact to be expected; at the extreme end, in such sectors, the shape is so flat that competition policy may be not an appropriate tool for boosting the research effort of firms.

However, more in-depth research are necessary to support such strong prescriptions. On the theoretical side, the size of innovations or firm size are partly endogenous to the competitive environment. Endogenizing them may alter our arguments. An other interesting avenue would also be to explore the effects of credit constraints, which particularly affect small innovative firms. Additional surveys by the Banque de France concerning these constraints could help to directly test the associated predictions.

In addition, recent papers have highlighted the joint effects of product market and labor market regulation on economic performances (see OECD, 2006, for a review); therefore the model's predictions also need to be tested for countries with more or less restrictive labor market regulations than France.

\section{References}

Aghion, P., Bloom, N., Blundell, R., Griffith, R., Howitt, P. (2002). "Competition and Innovation: An Inverted U Relationship". NBER Working Paper, nº9269.

Aghion, P., Bloom, N., Blundell, R., Griffith, R., Howitt, P. (2005). "Competition and Innovation: an Inverted-U Relationship". Quarterly Journal of Economics, 120(2), 701-728, May.

Chatelain, J.B., Tiomo, A. (2001). "Investment, the Cost of Capital and Monetary Policy in the Nineties in France: A Panel Data Investigation", ECB Working Paper No. 106.

Chatelain, J.-B., Generale, A., Hernando, I., von Kalckreuth, U., Vermeulen, P. (2003). "New Findings on Firm Investment and Monetary Transmission in the Euro Area ", Oxford Review of Economic Policy, 19(1), 73-83.

Cohen, W.M., Klepper, S. (1996). "A Reprise of Size and R\&D". The Economic Journal, 106, $925-951$.

Kremp, E. (1995). "Nettoyage de fichiers dans le cas de données individuelles, Recherche de la cohérence transversale". Economie et prévision, nº 119, vol.3, 171-193.

OECD, (2006). Employment Outlook, OECD, Paris. 
Savignac, F. (2007). "The Impact of Financial Constraints on Innovation: What Can Be Learned From a Direct Measure?", Economics of Innovation and New Technology, forthcoming.

Scherer, F.M., Ross D. (1990). "Industrial Market Structure and Economic Performance". $3^{\text {rd }}$ ed., Houghton Mifflin. 


\section{A Appendix: Proofs}

\section{A.1 Proof of proposition 1}

Let's note $\sigma_{0}$ and $\sigma_{-1}$ the first derivatives of the R\&D intensity with respect to product market competition respectively in the leveled and unleveled sectors. As regards neck-and-neck sectors, we have:

$$
\sigma_{0}=\frac{\partial n_{0}}{\partial \nu}=\frac{\chi}{2 \sqrt{(r+h)^{2}+\nu \chi}}
$$

with $\chi \equiv 2 \pi_{1} \Phi / \beta$. The first derivative of $\sigma_{0}$ with respect to $\gamma$ gives:

$$
\frac{\partial \sigma_{0}}{\partial \gamma}=\frac{\partial \chi}{\partial \gamma} \frac{2(r+h)^{2}+\nu \chi}{4\left((r+h)^{2}+\nu \chi\right)^{3 / 2}}
$$

which is of the sign of $\frac{\partial \chi}{\partial \gamma}$.

Since we have:

$$
\frac{\partial \chi}{\partial \gamma}=\frac{\partial}{\partial \gamma}\left(\frac{2\left(1-\frac{1}{\gamma}\right) \Phi}{\beta(\gamma)}\right)=\frac{2 \Phi}{\beta^{2}(\gamma)}\left(\frac{1}{\gamma^{2}} \beta(\gamma)-\left(1-\frac{1}{\gamma}\right) \beta^{\prime}(\gamma)\right)
$$

hence $\operatorname{sign}\left(\frac{\partial \chi}{\partial \gamma}\right)=\operatorname{sign}\left(\frac{1}{\gamma^{2}} \beta(\gamma)-\left(1-\frac{1}{\gamma}\right) \beta^{\prime}(\gamma)\right)$. Introducing $\Psi$ defined as:

$$
\Psi(\gamma)=\frac{1}{\gamma^{2}} \beta(\gamma)-\left(1-\frac{1}{\gamma}\right) \beta^{\prime}(\gamma)
$$

we have $\Psi^{\prime}(\gamma)=-\frac{2 \beta(\gamma)}{\gamma^{3}}-\beta^{\prime \prime}(\gamma)\left(1-\frac{1}{\gamma}\right)$, which is non positive for each $\gamma$ if $\beta$ is convex. Since we have $\Psi(1)=0, \Psi$, and consequently $\frac{\partial \chi}{\partial \gamma}$ is negative for each $\gamma>1$. As a result, $\sigma_{0}$ is a decreasing function of the size of innovation. This establishes Proposition 1 related to neck-and-neck sectors.

\section{A.2 Proof of corollary 1}

Since we have $\frac{\partial \sigma_{0}}{\partial \chi}>0$ according to the notation from the previous section, and as $\chi$ is increasing with respect to $\Phi$, the slope $\sigma_{0}$ is an increasing function of the firm's size. This establishes Corollary 1.

\section{A.3 Proof of proposition 2}

We first prove the following cases: assuming that the $R \& D$ cost function is convex and such as $\beta(\gamma)=o(1-1 / \gamma)$, for large or costly innovations $(\gamma \gg 1)$ as well as for small or cheap innovations $(\gamma \sim 1)$, the slope of the relationship between innovation and competition in the unleveled sectors is a non positive, increasing function of the size of innovation $\gamma$. 
For the size of innovation being in the neighborhood of 1 , which means that innovations are incremental, and under the assumption that $\beta(\gamma)=o(1-1 / \gamma)$, we have:

$$
\chi=\frac{2\left(1-\frac{1}{\gamma}\right) \Phi}{\beta(\gamma)} \gg 1
$$

So we find an equivalent of $n_{0}$ for large $\chi$ 's:

$$
n_{0} \underset{\chi \gg 1}{\sim}(\nu \chi)^{\frac{1}{2}}
$$

and so the research intensity in leveled sectors:

$$
n_{-1} \underset{\chi \gg 1}{\sim}(\sqrt{1+\nu}-\sqrt{\nu}) \chi^{\frac{1}{2}}
$$

As a consequence, we have the slope of the relationship between competition and R\&D intensity for small $\chi$ 's:

$$
\sigma_{-1}=\frac{\partial n_{-1}}{\partial \nu} \underset{\chi \gg 1}{\approx} \frac{\sqrt{\nu}-\sqrt{1+\nu}}{2 \sqrt{1+\nu} \sqrt{\nu}} \chi^{\frac{1}{2}}
$$

which is a non positive, increasing function of $\gamma$.

In a similar way, for costly innovations, i.e. large $\gamma$, we have:

$$
\chi=\frac{2\left(1-\frac{1}{\gamma}\right) \Phi}{\beta(\gamma)} \ll 1 .
$$

Hence, the first order approximation of $n_{0}$ for $\chi$ sufficiently small gives:

$$
n_{0}=\frac{\nu \chi}{2(r+h)}+o(\chi)
$$

It follows that the linear approximation of $n_{-1}$ is:

$$
n_{-1}=\frac{(1-\nu) \chi}{2(r+h)}+o(\chi)
$$

As a consequence, we have the slope of the relationship between competition and R\&D intensity for small $\chi$ 's:

$$
\sigma_{-1}=\frac{\partial n_{-1}}{\partial \nu} \underset{\chi \sim 0}{\approx}-\frac{\chi}{2(r+h)}
$$

which is a non positive, increasing function of $\gamma$.

The system of equations giving $n_{0}$ and $n_{-1}$ is quasi-homogenous in $r+h$. It can be thus rewritten as a non-parametric system as following.

Let $m_{0}=n_{0} /(r+h), m_{-1}=n_{-1} /(r+h)$ and $X=\pi_{1} \Phi /[\beta(r+h)]^{2}$. The system becomes

$$
m_{0}=-1+\sqrt{1+\nu X}
$$




$$
m_{-1}=-1-m_{0}+\sqrt{1+m_{0}^{2} X}
$$

Proving the proposition (i.e. showing that $\frac{\partial^{2} n_{-1}}{\partial \gamma \partial \nu}>0$ or $\frac{\partial^{2} n_{-1}}{\partial L \partial \nu}<0$ ) is then equivalent to show that $\frac{\partial^{2} n_{-1}}{\partial X \partial \nu}<0$, with $\left.\nu \in\right] 0 ; 1[$ and $X \in] 0 ;+\infty[$.

It is clearly true for large or small value of $\mathrm{X}$. But formal calculus does not allow proving this property for all X. Therefore, we use a numerical representation (see figure 3 ) of $\frac{\partial^{2} n_{-1}}{\partial X \partial \nu}$ on the field $(\nu, X) \in] 0 ; 1[\times] 0 ;+\infty[$. This completes the proof of Proposition 2 .

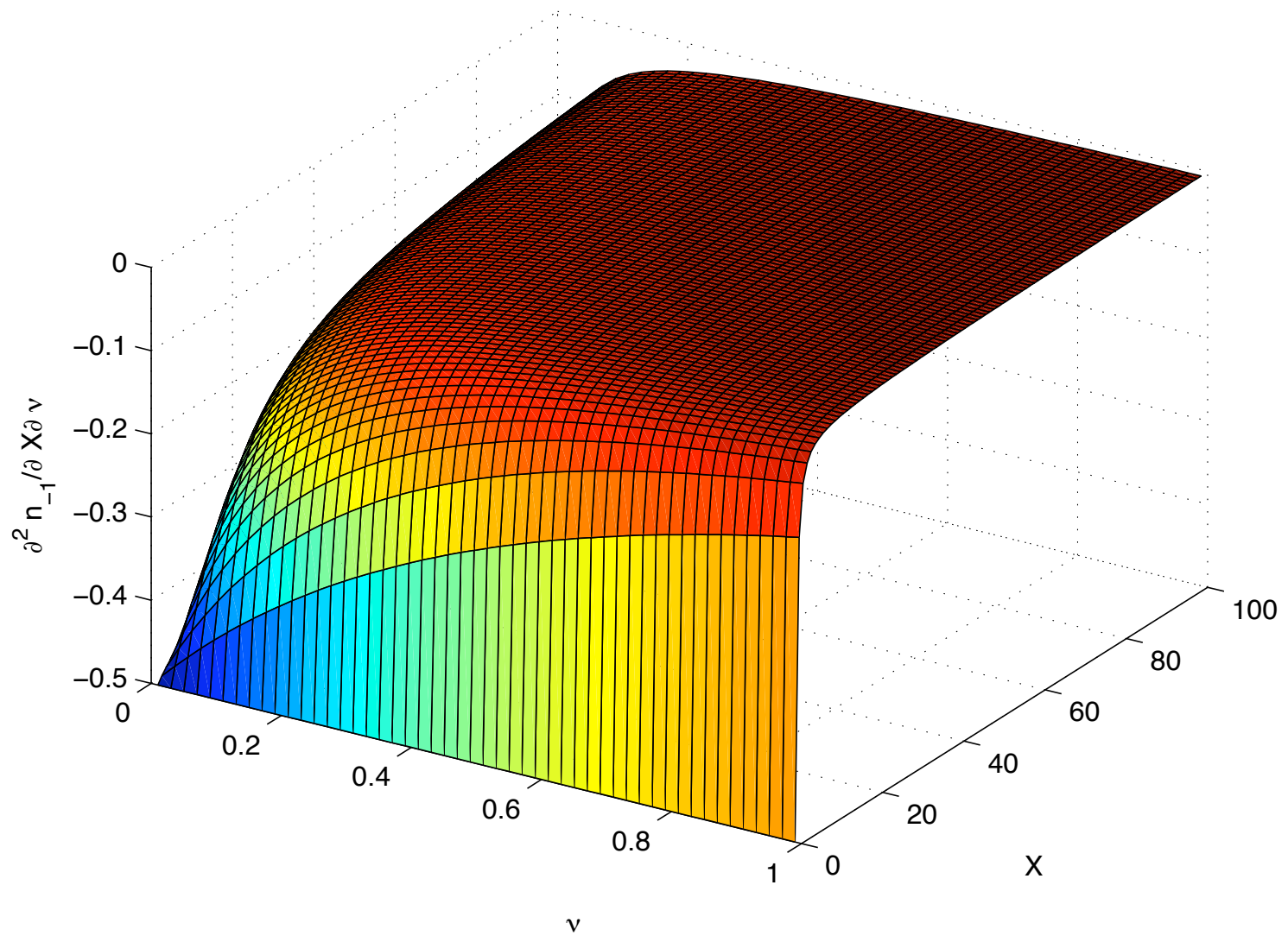

Figure 3: $\frac{\partial^{2} n_{-1}}{\partial X \partial \nu}$ on the field $\left.(\nu, X) \in\right] 0 ; 1[\times] 0 ;+\infty[$ 


\section{A.4 Theoretical counterpart of Lerner index at the firm level}

Based on this model, the theoretical counterpart of our empirical measure of competition, the Lerner index, is given by

$$
\begin{aligned}
\lambda_{0} & =(1-\nu)\left(1-\gamma^{-1}\right) \\
\lambda_{-1} & =0 \\
\lambda_{1} & =1-\gamma^{-1}
\end{aligned}
$$

where $\lambda_{0}, \lambda_{-1}$, and $\lambda_{1}$ are related to leveled, follower, and leader firm respectively. Hence, the Lerner index decreases with competitive pressure for neck-and-neck firms, whereas the Lerner index depends positively on the size of innovation. For a given firm, the expected Lerner index is then given by

$$
\begin{aligned}
\mathbb{E}(\lambda) & =\mu_{0} \lambda_{0}+\frac{\mu_{1}}{2} \lambda_{-1}+\frac{\mu_{1}}{2} \lambda_{1} \\
& =\left(1-\mu_{1}\right)(1-\nu)\left(1-\gamma^{-1}\right)+\frac{\mu_{1}}{2}\left(1-\gamma^{-1}\right)
\end{aligned}
$$

The marginal effect of a change in the Lerner index on innovation is decreasing with $\gamma$.

\section{A.5 Description of the sample}

Table 5: Distribution of observations by main sectors (NES 16) in \%

\begin{tabular}{lc}
\hline \hline Agriculture, hunting, forestry, and fishing & 1.1 \\
Food and agricultural manufacturing & 5.4 \\
Consumer goods manufacturing & 8.2 \\
Car manufacturing & 1.7 \\
Equipment good manufacturing & 17.0 \\
Intermediary good manufacturing & 20.7 \\
Energy & 0.5 \\
Construction & 4.7 \\
Gross and retail trade & 21.3 \\
Transport & 3.0 \\
Real estate & 0.7 \\
Business sectors & 14.0 \\
Services & 1.9 \\
\hline
\end{tabular}


Table 6: Descriptive statistics

\begin{tabular}{lcccccc}
\hline \hline Variable & mean & std. dev. & $25 \%$ & median & $75 \%$ & Obs. \\
\hline $\begin{array}{l}\text { Patent unit cost } \kappa_{s}, \text { in thou- } \\
\text { sands of euros }\end{array}$ & 1,696 & 2,258 & 490 & 822 & 1,959 & 142 \\
$\begin{array}{l}\text { Patent unit cost per employee } \\
\kappa_{s} / L_{j}\end{array}$ & 72.3 & 203.3 & 9.2 & 24.4 & 65.3 & 99,557 \\
$\begin{array}{l}\text { patent unit cost, firm level, in } \\
\text { logarithm } \ln (\kappa)\end{array}$ & 6.68 & 0.93 & 6.18 & 6.58 & 7.22 & 100,042 \\
$\begin{array}{l}\text { Lerner index (lagged) } \\
\text { Individual innovation flow, } n_{j}\end{array}$ & 0.057 & 0.17 & 0.20 & 0.30 & 0.42 & 100,042 \\
\hline \hline
\end{tabular}

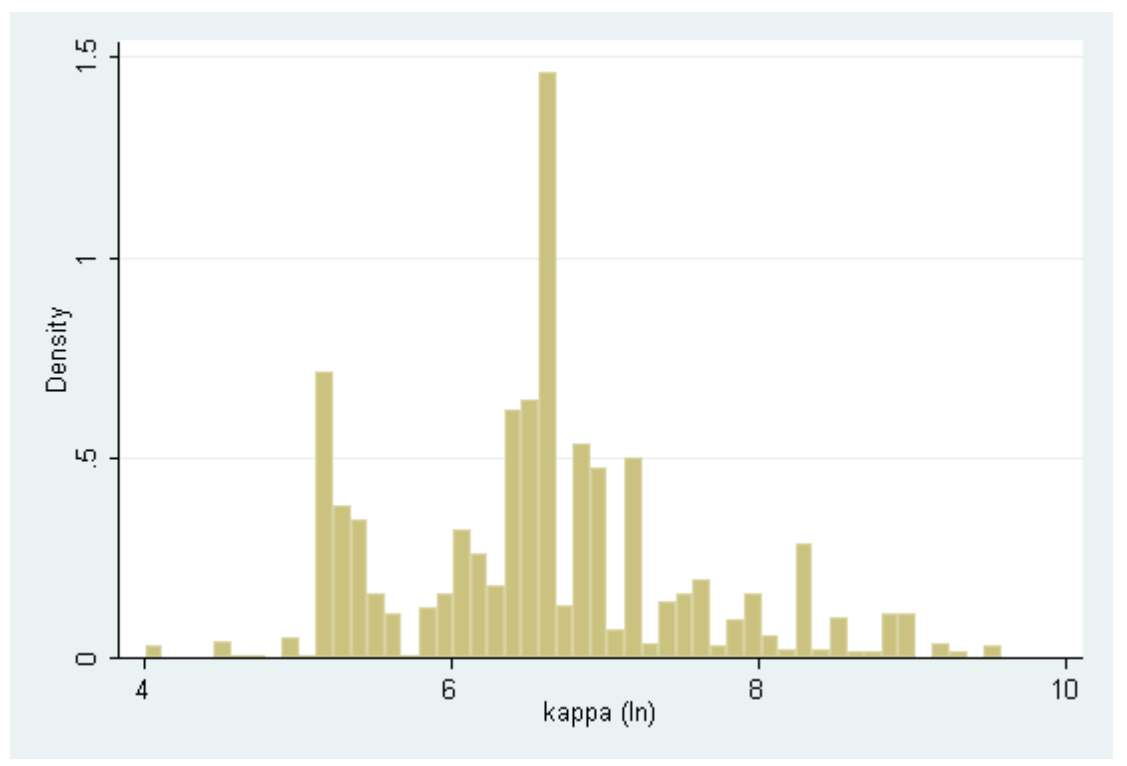

Figure 4: Distribution of $\ln (\kappa)$ 